\title{
GMR
}

\section{Classification and phylogenetic analysis of Chinese hawthorn assessed by plant and pollen morphology}

\author{
S.L.Y. Ma and Y.M. Lu \\ College of Landscape Architecture, Beijing Forestry University, Beijing, China \\ Corresponding author: Y.M. Lu \\ E-mail: luyingmin@bjfu.edu.cn / masuliya@bjfu.edu.cn \\ Genet. Mol. Res. 15 (3): gmr.15038739 \\ Received April 27, 2016 \\ Accepted July 14, 2016 \\ Published September 19, 2016 \\ DOI http://dx.doi.org/10.4238/gmr.15038739
}

Copyright $(2016$ The Authors. This is an open-access article distributed under the terms of the Creative Commons Attribution ShareAlike (CC BY-SA) 4.0 License.

\begin{abstract}
The Chinese hawthorn (Crataegus pinnatifida Bge. var. major N.E.Br.) is uniquely originated in northern China. The ecological and horticultural importance of Chinese hawthorn is considerable and some varieties are valued for their fruit or medicine extracts. Its taxonomy and phylogeny remain poorly understood. Apart from general plant morphological traits, pollen is an important trait for the classification of plants and their evolutionary origin. However, few studies have investigated the pollen of Chinese hawthorn. Here, an analysis of plant and pollen morphological characteristics was conducted in 57 cultivars from the Shenyang region. Thirty plant morphological characters and nine pollen grain characters were investigated. The plant morphological analysis revealed that the coefficient of variation for 13 traits was $>20 \%$, which indicates a high degree of variability. We also found that the pollen grains varied greatly in size, shape (from prolate to perprolate), and exine pattern (striate-perforate predominantly). The number of apertures was typically three. Based on these findings, we
\end{abstract}


suggest that pollen morphology associated with plant morphological traits can be used for classification and phylogenetic analysis of Chinese hawthorn cultivars. In sum, our results provide new insights and constitute a scientific basis for future studies on the classification and evolution of Chinese hawthorn.

Key words: Chinese hawthorn; Variability; Classification; Morphological traits; Pollen morphology

\section{INTRODUCTION}

Hawthorn (Crataegus spp) has a wide distribution in the temperate regions of the Northern Hemisphere. Some species are grown for food or medicine in Asia, North and Central America, and Mediterranean countries, whereas others serve as ornamental plants in Europe and North America (Christensen, 1983, 1992; Dönmez, 2008). The genus Crataegus traditionally belongs to the Rosaceae family, subfamily Maloideae, tribe Crataegeae (Phipps, 1988; Phipps et al., 1991; Christensen, 1992). In follow-up studies, Campbell et al. (2007) proposed that Crataegus was included in the subtribe Pyrinae (formerly subfamily Maloideae); and according to Christensen and Zieliński (2008) Crataegus was in the tribe Pyrinae.

Crataegus has a complicated taxonomic history. Dönmez (2008) suggested that the taxonomy of Crataegus is problematic owing to biological, historical, and many other factors. In particular, the taxonomic problems and the description of a large number of new species are the result of intergeneric hybridization (Phipps, 2005). To these factors are added introgression, extensive polyploidy, and gametophytic apomixis, which may occur and blur the boundaries between species (Christensen, 1992). The roles of hybridization and apomixes

have been considered to be minimal. The systematics of the genus is still in question, not only because numerous species have been described by several authors, but the circumscription of the species has varied widely (Christensen, 1992; Dönmez, 2008; Wrońska-Pilarek et al., 2013). Depending on the species concept employed, there is no general consensus on the number of species. Fineschi et al. (2005) reviewed the number of Crataegus species in different regions described by several authors and observed that the proposed number of species varied greatly. Including numerous hybrids and variants, the genus Crataegus has been suggested to contain between 140 and 200 species (Lo, 2008; Dai et al., 2007, 2009, 2013). According to Judd et al. (1999), the genus Crataegus comprises 265 species. Other researchers supposed that regarding nearly all geographically and morphologically deviating groups as different species resulted in an even higher number of species (Albarouki and Peterson, 2007; Khadivi-Khub et al., 2015). The most acceptable viewpoint is that the genus compromises approximately 150-1200 species (Christensen, 1992; Albarouki and Peterson, 2007; Wrońska-Pilarek et al., 2013).

In China, both the wild germplasm and cultivated varieties of hawthorn are abundant. Some previous Chinese researchers adopt the viewpoint there were more than 1000 species in the genus Crataegus worldwide (Guo and Jiao, 1995; Zhao and Feng, 1996). In China, 18 species and 6 botanical variations have been identified and confirmed (Zhao and Feng, 1996). Among these, the large fruited (6-17 g) Chinese hawthorn (Crataegus pinnatifida Bge. var. major N.E.Br.) originated in northern China and is represented by more than 100 cultivars (Dai et al., 2007, 2009). At about A.D. 1000, the cultivation of hawthorn started. With its potential therapeutic value and use in medicines, hawthorn is regarded as "fruits for good health" (Guo

Genetics and Molecular Research 15 (3): gmr.15038739 
and Jiao, 1995). It is primarily used to improve digestion due to its high content of Crataegus acid. It is also used as an alternative therapy for various cardiovascular conditions, because of its flavonoid content (Rigelsky and Sweet, 2002; Kao et al., 2005). Also with high amount of flavonoid, vitamin C, glycoside, anthocynaidin, and other components, the fruits could be used for fresh consumption (eaten raw) or processed in the form of jam, jelly, syrup, juice, preserves, and preserved slices (Dai et al., 2007, 2009, 2013).

The classification of existing hawthorn varieties is historically complicated and is still in a state of confusion in China. There have been several studies on its classification, but most have focused on the morphological characters. In contrast, few studies have used palynological (studies of pollen), chromosomal, and molecular methods, which may be significantly more efficient for modifying the classification. Zhao and Feng (1996) considered species the firstorder criterion, and then classified Chinese hawthorn cultivars into three groups based on fruit colors (red, orange, and yellow fruit group). This classification has been adopted widely and is used for practical application to date. Despite this taxonomic system, it is difficult to classify several varieties of Chinese hawthorn based on morphological traits alone, given that some traits are shared by different varieties, species, and even distantly related species. Researchers have since come to realize the significance of pollen morphology in clarifying the classification. Pollen grains could be regarded as functional units, with functions such as: protective, harmomegathic, reservoir, and clustering (Muller, 1979; Du et al., 2014).

In our study, plant and pollen morphological traits of 57 Chinese hawthorn cultivars were investigated. Previous similar investigations have been based on the analysis of selected quantitative and qualitative features. The aims of our study were to increase the knowledge of aspects related to the classification and phylogenetic analysis of Chinese hawthorn, to provide a detailed morphological investigation of Chinese hawthorn pollen.

\section{MATERIAL AND METHODS}

\section{Plant materials}

The cultivars chosen from Chinese hawthorn consisted of 57 cultivated species belonging to $C$. pinnatifida Bge. var. major N.E.Br. The trees of Chinese hawthorn cultivars were maintained in the National Hawthorn Germplasm Repository at Shenyang Agricultural University, China. The trees selected for our investigation were all labeled and documented photographically. As an example, pictures from 'Shuanghong' inflorescence (Figure 1A), flower (Figure 1B), leaf (Figure 1C), fruit (Figure 1D and E), flesh (Figure 1E) and endocarp (Figure 1F) are shown in Figure 1. The entire list of cultivars used in this study along with numeral orders and cultivar names are presented in Table 1. We ensured that our study had no adverse effects of Chinese hawthorn trees.

\section{Plant morphology measurements}

The International Union for the Protection of New Varieties of Plants (UPOV) issued the Guideline for the Conduct of Tests for Distinctness, Uniformity and Stability (Crataegus L.) (UPOV/TG/239/1) in 2008. According to the guidance from the UPOV and previous studies conducted by Christensen (1992), Albarouki and Peterson (2007), and Khadivi-Khub et al. (2015), 30 neutral-like traits were selected for analysis of phenotypic variation and classification.

Genetics and Molecular Research 15 (3): gmr.15038739 

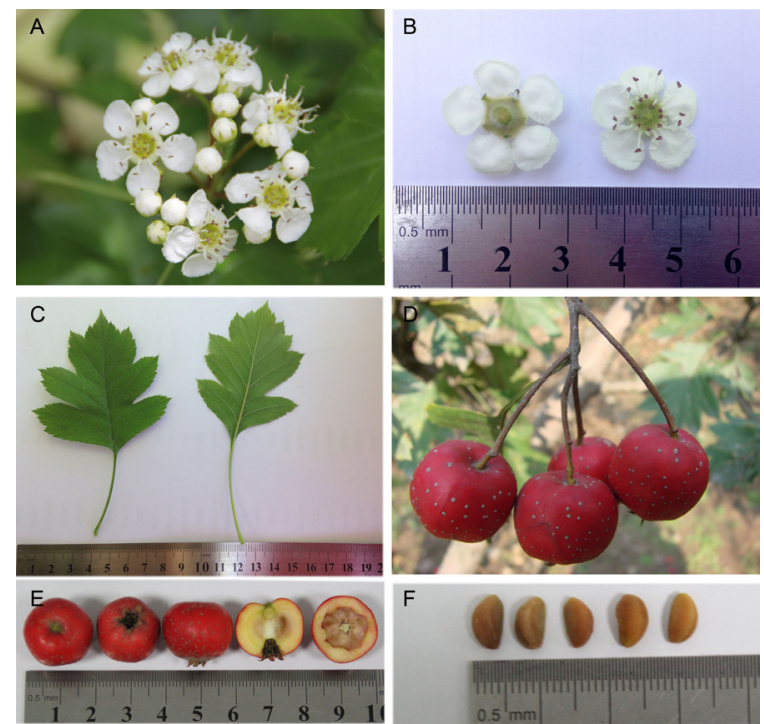

Figure 1. A. Inflorescence of 'Shuanghong'. B. Flower of 'Shuanghong'. C. Leaves of 'Shuanghong'. D. and E. Fruits and flesh of 'Shuanghong'. F. Endocarps of 'Shuanghong'.

Table 1. List of the studied accessions of Chinese hawthorn.

\begin{tabular}{|c|c|c|c|}
\hline No. & Cultivar & No. & Cultivar \\
\hline 1 & C. pinnatifida var. major 'Baihuayudajinxing' & 30 & C. pinnatifida var. major 'Pingyishanzha' \\
\hline 2 & C. pinnatifida var. major 'Beijingshanzha' & 31 & C. pinnatifida var. major 'Qiujinxing' \\
\hline 3 & C. pinnatifida var. major 'Chaojinxing' & 32 & C. pinnatifida var. major 'Shanxitiansheng' \\
\hline 4 & C. pinnatifida var. major 'Dawuleng' & 33 & C. pinnatifida var. major 'Shangzhuanbaizha' \\
\hline 5 & C. pinnatifida var. major 'Donglingqingkou' & 34 & C. pinnatifida var. major 'Shenglizirou' \\
\hline 6 & C. pinnatifida var. major 'Feixiandamianqiu' & 35 & C. pinnatifida var. major 'Shuiyingshanzha' \\
\hline 7 & C. pinnatifida var. major 'Fenli' & 36 & C. pinnatifida var. major 'Sishanling' \\
\hline 8 & C. pinnatifida var. major 'Fense' & 37 & C. pinnatifida var. major 'Tianshui' \\
\hline 9 & C. pinnatifida var. major 'Ganyu-2' & 38 & C. pinnatifida var. major 'Tianxiangyu' \\
\hline 10 & C. pinnatifida var. major 'Guhong' & 39 & C. pinnatifida var. major 'Tonghuashanzha' \\
\hline 11 & C. pinnatifida var. major 'Guajiayu-1' & 40 & C. pinnatifida var. major 'Tongliaohong' \\
\hline 12 & C. pinnatifida var. major 'Hanluhong' & 41 & C. pinnatifida var. major 'Xifen-1' \\
\hline 13 & C. pinnatifida var. major 'Hezedashanzha' & 42 & C. pinnatifida var. major 'Xifen-4' \\
\hline 14 & C. pinnatifida var. major 'Hongshiliu' & 43 & C. pinnatifida var. major 'Xifen-5' \\
\hline 15 & C. pinnatifida var. major 'Huixiandahong' & 44 & C. pinnatifida var. major 'Xiaohuangmianzha' \\
\hline 16 & C. pinnatifida var. major 'Jiangxianshanzha' & 45 & C. pinnatifida var. major 'Xiezishi-1' \\
\hline 17 & C. pinnatifida var. major 'Jinxing' & 46 & C. pinnatifida var. major 'Xinbin-7' \\
\hline 18 & C. pinnatifida var. major 'Jingduan-1' & 47 & C. pinnatifida var. major 'Xingshiliu' \\
\hline 19 & C. pinnatifida var. major 'Jiuzhaishanzha' & 48 & C. pinnatifida var. major 'Xinghong-3' \\
\hline 20 & C. pinnatifida var. major 'Kaiyuan-1' & 49 & C. pinnatifida var. major 'Xinglongzirou' \\
\hline 21 & C. pinnatifida var. major 'Laiwuheihong' & 50 & C. pinnatifida var. major 'Yanranghong' \\
\hline 22 & C. pinnatifida var. major 'Liaohong' & 51 & C. pinnatifida var. major 'Yiduchangkou' \\
\hline 23 & C. pinnatifida var. major 'Liaoning-10' & 52 & C. pinnatifida var. major 'Yiduxiaohuang' \\
\hline 24 & C. pinnatifida var. major 'Linxianshangkou' & 53 & C. pinnatifida var. major 'Yinyeling-1' \\
\hline 25 & C. pinnatifida var. major 'Linfenxiaoguo' & 54 & C. pinnatifida var. major 'Yubeihong' \\
\hline 26 & C. pinnatifida var. major 'Majiadadui' & 55 & C. pinnatifida var. major 'Zaohong' \\
\hline 27 & C. pinnatifida var. major 'Majiafenrou' & 56 & C. pinnatifida var. major 'Zaohanghongshiliu' \\
\hline 28 & C. pinnatifida var. major 'Mengyindajinxing' & 57 & C. pinnatifida var. major 'Zimuhong' \\
\hline 29 & C. pinnatifida var. major 'Pingyidahongzi' & & \\
\hline
\end{tabular}

Genetics and Molecular Research 15 (3): gmr.15038739 
The measurement methods of these plant morphological traits followed the UPOV guidelines and the references mentioned above. Twenty characters, including plant habit, leaf shape, leaf blade lobes, leaf blade margin, delicate leaf color, etc., were coded and rated as shown in Table 2. The descriptive statistics are based on 10 samples for the flower-, leaf-, and endocarprelated measurements and 30 samples for the fruit-related measurements (Table 3). Flowers were sampled at full bloom (around mid-May in Shenyang), leaves were sampled when they were mature and fruits were sampled at ripening time (around the beginning of October in Shenyang).

Table 2. Code and states of the studied accessions of Chinese hawthorn.

\begin{tabular}{l|l|l}
\hline No. & Variable & Evaluation of qualitative polymorphic characters \\
\hline 1 & Plant: habit & 1 fastigiate 2 upright 3 spreading \\
\hline 2 & Leaf blade: shape & 1 ovate 2 wide ovate 3 triangle ovate 4 rhomboid ovate \\
\hline 3 & Leaf blade: lobes & 3 shallow lobe 5 medium lobe 7 deep lobe \\
\hline 4 & Leaf blade: margin & 1 wide saw tooth 2 thin saw tooth \\
\hline 5 & Delicate leaf: color & 1 light green 2 light red 3 brown red \\
\hline 6 & Inflorescence: number of flowers & 3 few 5 medium 7 many \\
\hline 7 & Inflorescence: indumentum & 1 absent 2 present \\
\hline 8 & Pedicel: length & 3 short 5 medium 7 long \\
\hline 9 & Flower: diameter & 3 small 5 medium 7 large \\
\hline 10 & Fruit: number of fruit per inflorescence & 3 few 5 medium 7 many \\
\hline 11 & Fruit: shape & 1 near circular 2 oblate 3 obovate 4 elliptic 5 near square \\
\hline 12 & Fruit: color & 1 yellow 2 orange red 3 red \\
\hline 13 & Fruit: texture of surface & 1 smooth or slightly rough 2 moderately rough 3 very rough \\
\hline 14 & Fruit: density of lenticels & 1 sparse 3 medium 5 dense 7 very dense \\
\hline 15 & Fruit: flesh texture & 1 floury 3 soft 5 firm 7 hard \\
\hline 16 & Fruit: flesh color & 1 green 2 yellow 3 pink 4 red 5 purple \\
\hline 17 & Fruit: shape of stalk base & 1 normal 2 tubercle one side 3 expansive \\
\hline 18 & Fruit: cavity of eye basin & 1 closed 2 open \\
\hline 19 & Sepals: shape & 1 lanceolate 2 triangle \\
\hline 20 & Sepals: posture & 1 open and endlong 2 open and flat 3 open and curled inverted 4 converge and curled inverted \\
\hline
\end{tabular}

Table 3. Descriptive statistics for 30 morphological characters in the studied accessions of Chinese hawthorn.

\begin{tabular}{|c|c|c|c|c|c|c|c|}
\hline No. & Variable & Unit & Min. & Max. & Mean & SD & $\mathrm{CV}(\%)$ \\
\hline 1 & Plant: habit & Code & 1 & 3 & 1.89 & 0.56 & 29.47 \\
\hline 2 & Leaf blade: shape & Code & 1 & 4 & 1.93 & 0.90 & 46.84 \\
\hline 3 & Leaf blade: lobes & Code & 3 & 7 & 5.28 & 1.49 & 28.13 \\
\hline 4 & Leaf blade: margin & Code & 1 & 2 & 1.68 & 0.47 & 27.92 \\
\hline 5 & Leaf blade: length & $\mathrm{cm}$ & 9.01 & 16.77 & 13.17 & 1.70 & 12.93 \\
\hline 6 & Leaf blade: width & $\mathrm{cm}$ & 5.67 & 11.66 & 8.38 & 1.12 & 13.34 \\
\hline 7 & Leaf shape index: length/width ratio & 1 & 1.29 & 1.96 & 1.58 & 0.15 & 9.22 \\
\hline 8 & Petiole: length & $\mathrm{cm}$ & 2.38 & 6.05 & 3.97 & 0.72 & 18.03 \\
\hline 9 & Delicate leaf: color & Code & 1 & 3 & 1.68 & 0.63 & 37.56 \\
\hline 10 & Inflorescence: number of flowers & Code & 3 & 7 & 4.75 & 0.76 & 16.06 \\
\hline 11 & Inflorescence: indumentum & Code & 1 & 2 & 1.26 & 0.44 & 35.24 \\
\hline 12 & Pedicel: length & Code & 3 & 7 & 4.93 & 1.51 & 30.63 \\
\hline 13 & Flower: diameter & Code & 5 & 7 & 5.14 & 0.52 & 10.02 \\
\hline 14 & Fruit: number of fruit per inflorescence & Code & 3 & 7 & 5.04 & 0.71 & 14.01 \\
\hline 15 & Fruit: shape & Code & 1 & 5 & 4.12 & 1.44 & 34.95 \\
\hline 16 & Fruit: color & Code & 1 & 3 & 2.79 & 0.49 & 17.60 \\
\hline 17 & Fruit: texture of surface & Code & 1 & 3 & 2.51 & 0.78 & 31.16 \\
\hline 18 & Fruit: density of lenticels & Code & 1 & 7 & 5.14 & 1.60 & 31.07 \\
\hline 19 & Fruit: flesh texture & Code & 1 & 7 & 4.96 & 1.58 & 31.88 \\
\hline 20 & Fruit: flesh color & Code & 1 & 5 & 2.42 & 0.82 & 34.01 \\
\hline 21 & Fruit: shape of stalk base & Code & 1 & 3 & 2.00 & 0.27 & 13.35 \\
\hline 22 & Fruit: cavity of eye basin & Code & 1 & 2 & 1.96 & 0.19 & 9.49 \\
\hline 23 & Fruit: length & $\mathrm{cm}$ & 1.73 & 2.81 & 2.24 & 0.26 & 11.52 \\
\hline 24 & Fruit: width & $\mathrm{cm}$ & 1.64 & 2.50 & 2.06 & 0.21 & 10.15 \\
\hline 25 & Fruit shape index: width/length ratio & 1 & 0.75 & 1.03 & 0.93 & 0.06 & 6.84 \\
\hline 26 & Sepals: shape & Code & 1 & 2 & 1.84 & 0.37 & 20.00 \\
\hline 27 & Sepals: posture & Code & 1 & 4 & 2.89 & 0.52 & 18.13 \\
\hline 28 & Endocarp: length & $\mathrm{cm}$ & 0.70 & 1.19 & 0.94 & 0.11 & 11.75 \\
\hline 29 & Endocarp: width & $\mathrm{cm}$ & 0.32 & 0.72 & 0.46 & 0.07 & 14.40 \\
\hline 30 & Endocarp shape index: width/length ratio & 1 & 0.38 & 0.89 & 0.50 & 0.08 & 16.38 \\
\hline
\end{tabular}

Genetics and Molecular Research 15 (3): gmr.15038739 


\section{Pollen morphology observations}

The palynological terminology followed that of Punt et al. $(1994,2007)$. The preparatory work before the scanning electron microscopy (SEM) followed Du et al. (2014) and Wang et al. (2016), with slight modifications. For the purpose of collecting pollen grains, flower buds of Chinese hawthorn cultivars were collected at the balloon stage, just before the opening of the anthers. The sepals and petals of the flower buds were removed and the isolated anthers were placed onto Petri dishes and kept at room temperature for $48 \mathrm{~h}$. The anthers were then broken to release the pollen grains. Dry pollen grains were directly mounted onto the surface of polished aluminum stubs with double-sided adhesive tape. After each stub was sputter-coated with a gold layer, the samples were taped to the object stage. Subsequent observation and micrograph acquisition were carried out with SEM (S-3400, Hitachi) at the Biotechnology Centre of Beijing Forestry University.

For each sample, the size of 30 pollen grains was measured, whereas all other measurements were based on 10 pollen grains. Only randomly chosen, fully mature, and correctly formed pollen grains were studied. Four quantitative features were analyzed: the length of the polar axis ( $\mathrm{P}$, straight line between the proximal and distal faces of a pollen grain), equatorial diameter (E, dividing line between the proximal and distal faces), the length of ectocolpi (Le); the distance between two colpi at the apices (d), and three ratios: P/E, Le/P, and d/E. The d/E ratio is commonly called the polar area index (PAI). Measurements of all parameters were made using Image-Pro plus v. 6.0. Arithmetic means and standard deviations were calculated for each parameter. Two qualitative features were also analyzed: pollen exine ornamentation and pollen shape. The description of pollen shape was based on the P/E ratio according to Erdtman's (1952) classification: oblate-spheroidal (0.89-0.99); spheroidal (1.00); prolate-spheroidal (1.01-1.14); subprolate (1.15-1.33); prolate (1.34-2.00); or perprolate $(>2.01)$.

\section{Data analysis}

The raw data was calculated in Microsoft Excel 2010 and all statistical analyses were performed in SPSS v. 19.0. Firstly, a descriptive analysis was performed to characterize the existing variation in all 57 cultivars. The following parameters were evaluated: minimum value, maximum value, arithmetic mean, standard deviation, and coefficient of variation $(\mathrm{CV}$, $\%)$. Correlations between the 30 plant morphological traits were determined using Pearson correlation coefficients. The collected data were also analyzed by principal component analysis (PCA) and cluster analysis to study the relationships among cultivars. Mean values were used to establish a correlation matrix from which standardized principal component (PC) scores were extracted. From the PCA, 28 key plant traits were obtained and selected for Q-cluster analysis. Another Q-cluster analysis was conducted with the nine pollen morphology traits, i.e., P, E, P/E, Le, Le/P, d, d/E, shape, and exine pattern. The Euclidean coefficient distance factor was adopted as the genetic distance of clustering units.

\section{RESULTS}

\section{Plant morphological description and variability}

Based on the $\mathrm{CV}$ values in the studied germplasm, we noticed that the majority of the

Genetics and Molecular Research 15 (3): gmr.15038739 
examined plant traits exhibited different degrees of variability. The CV ranged from $6.84 \%$ (fruit shape index) to $46.84 \%$ (leaf blade shape). Also, the CVs of 13 traits exceeded 20\%, which highlights the existence of a high degree of variability (Table 3 ).

'Majiadadui' had the greatest leaf blade length and width $(16.77$ and $11.66 \mathrm{~cm}$, respectively), whereas 'Beijingshanzha' was the accession with the smallest leaf blade length and width $(9.01$ and $5.67 \mathrm{~cm}$, respectively). The leaf shape index varied from 1.29 (in 'Xinglongzirou') to 1.96 (in 'Xingshiliu'). The petiole length ranged from 2.38 (in 'Xinglongzirou') to $6.05 \mathrm{~cm}$ (in 'Fense'). The greatest fruit length and width were from 'Feixiandamianqiu' $(2.81 \mathrm{~cm})$ and 'Yinyeling-1' $(2.50 \mathrm{~cm})$, whereas the smallest fruit length and width were from 'Yanranghong' $(1.73 \mathrm{~cm})$ and 'Shuiyingshanzha' $(1.64 \mathrm{~cm})$. For the endocarp measurements, the greatest endocarp length and width were recovered from 'Dawuleng' $(1.19 \mathrm{~cm})$ and 'Yinduchangkou' $(0.72 \mathrm{~cm})$, whereas the smallest endocarp length and width were from 'Yiduxiaohuang' $(0.70 \mathrm{~cm})$ and 'Sishanling' $(0.32 \mathrm{~cm})$.

The studied cultivars differed in plant habit. In some cultivars, the plant was fastigiated (12 cultivars), 39 cultivars were upright, and six cultivars had a spreading habit. Thus, the dominant plant habit was upright. The leaf blade shape included ovate (23 cultivars), wide ovate (17 cultivars), triangle ovate (15 cultivars), and rhomboid ovate (two cultivars). Most of cultivars possessed ovate leaves. The leaf lobes varied from shallow (12 cultivars) to deep (20 cultivars), and 25 cultivars showed medium lobes. In the inflorescence, the number of flowers, pedicel length, flower diameter, and number of fruits per inflorescence varied from low to high. The number of flowers ranged from few (in 8 cultivars), medium (in 48 cultivars), to many (in 1 cultivar). Pedicel length was short in 17 cultivars, medium in 25 cultivars, and long in 15 cultivars. The number of fruits per inflorescence was few in 19 cultivars, intermediate in 16 cultivars, and many in 35 cultivars. Fruit shape showed great polymorphism among the studied cultivars including near circular ( 4 cultivars), oblate (10 cultivars), obovate (1 cultivar), elliptic ( 2 cultivars), and near square (40 cultivars). The cavity of the fruit eye basin was predominantly open (55 cultivars). The sepal shape was lanceolate in 9 cultivars and triangle-shaped in 48 cultivars.

\section{General pollen characteristics}

A description of the pollen morphology of Chinese hawthorn studied was presented in Figures 2 and 3 and illustrated in SEM micrographs (Figure 4A-E). The pollen grains of all investigated cultivars occurred as monads, were symmetric (with two or more vertical planes of symmetry), isopolar (the distal and proximal faces look alike), trizonocolpate (with three germinal furrows or colpi), and variable in size. The mean length of P measured 36.89$50.07 \mu \mathrm{m}$, and the average length of $\mathrm{E}$ was 19.65-27.04 $\mu \mathrm{m}$. Among the 57 cultivars, the smallest $\mathrm{P}$ were found in the pollen of 'Xiaohuangmianzha' $(30.79 \mu \mathrm{m})$ and the largest in 'Beijingshanzha' (53.74 $\mu \mathrm{m})$. In contrast, the smallest E occurred in 'Tonghuashanzha' (18.46 $\mu \mathrm{m})$, and the largest in 'Feixiandamianqiu' $(30.15 \mu \mathrm{m})$. The ratio of $\mathrm{P} / \mathrm{E}$ ranged from 1.18 to 2.37, and the PAI (d/E) ranged from 0.07 to 0.39. According to Erdtman's (1952) pollen size classification, almost all of the studied pollen grains were of medium size. Our investigation showed that the pollen grains of Chinese hawthorn usually possessed three apparent apertures (Figure 2A and B). The most frequent aperture form was tricolporate. The colpi were arranged meridionally, regularly, fusiform in outline, and ranged from 27.31 (in 'Liaohong') to 49.25 $\mu \mathrm{m}$ (in 'Huixiandahong'). The most frequent pollen grain shape was prolate (Figure $2 \mathrm{C}$ and

Genetics and Molecular Research 15 (3): gmr.15038739 
D). Oblate, oblate-spheroidal, spheroidal, prolate-spheroidal, and subprolate pollen grains were not observed in any cultivars. Concerning the outline of the pollen grains, in the polar view, they were generally circular, whereas they were transversely elliptic in the equatorial view (Figure 2).
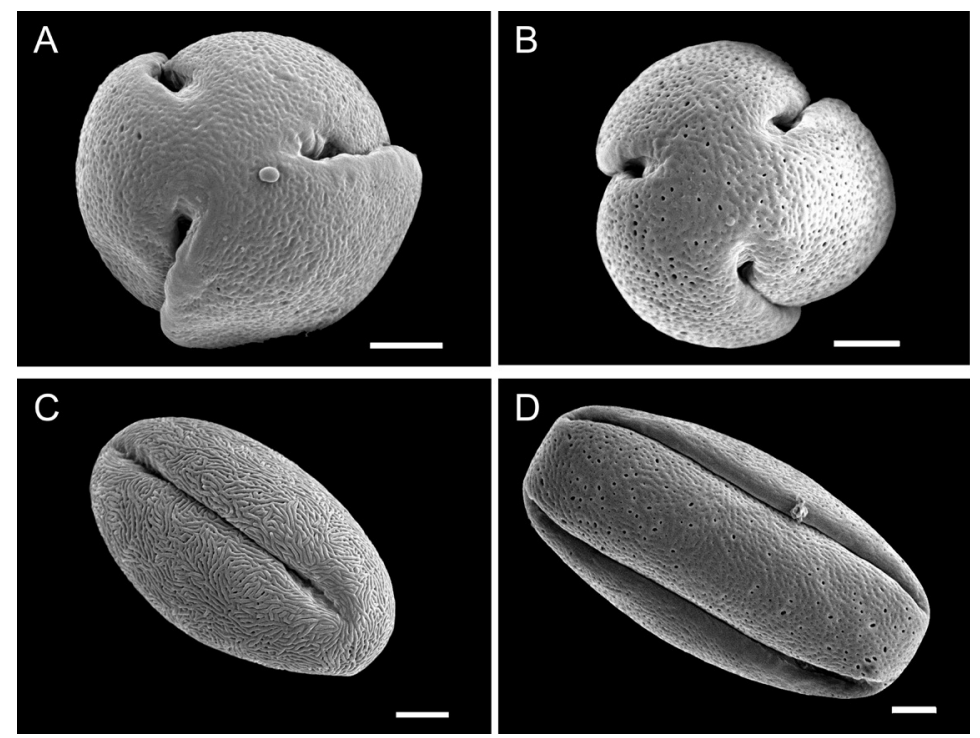

Figure 2. A. Pollen grains in polar view. B. Pollen grains in equatorial view. C. Pollen grains of prolate shape. D. Pollen grains of perprolate shape (Scale bar: $5 \mu \mathrm{m}$ ).
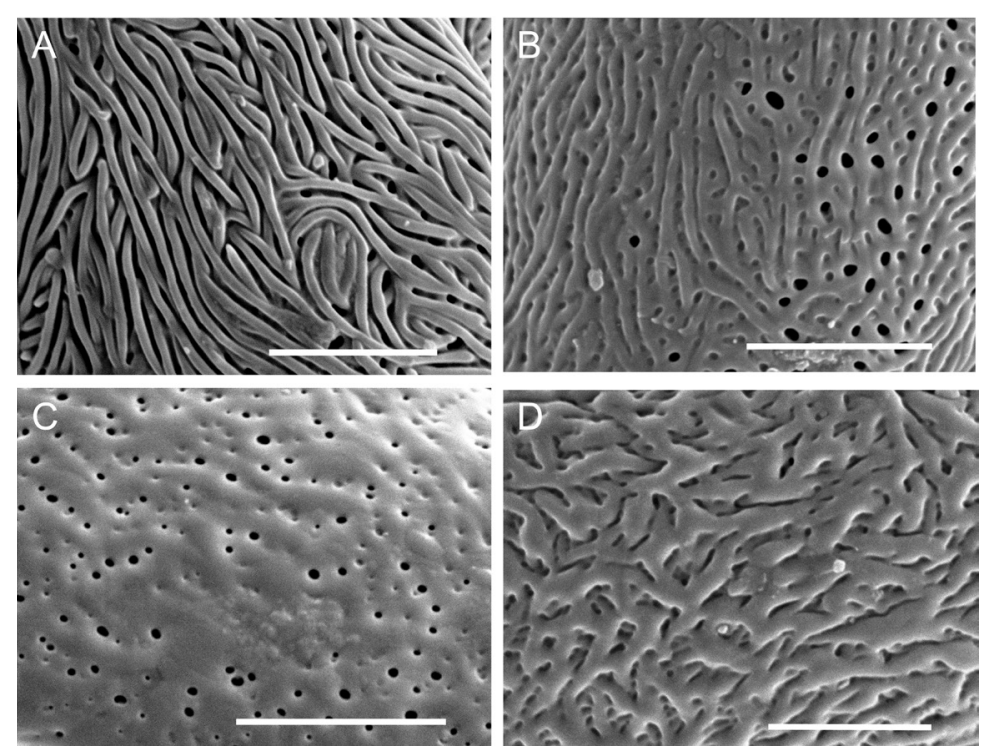

Figure 3. A. Pollen exine of striate-perforate $(\mathrm{m}>\mathrm{g})$. B. Pollen exine of striate-perforate $(\mathrm{m} \approx \mathrm{g})$. C. Pollen exine of perforate. D. Pollen exine of rugulate (Scale bar: $5 \mu \mathrm{m}$ ). 
A

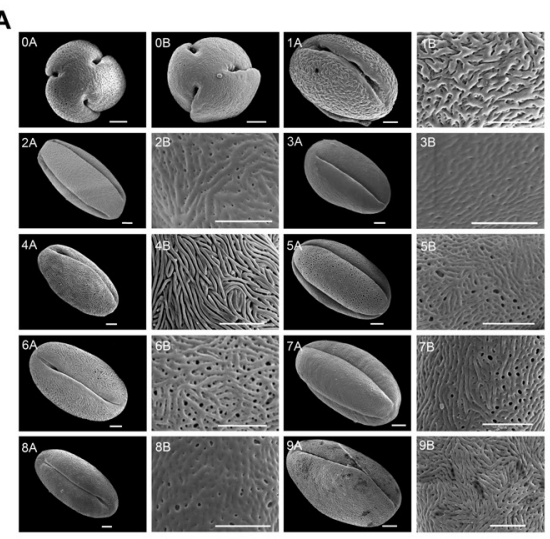

C

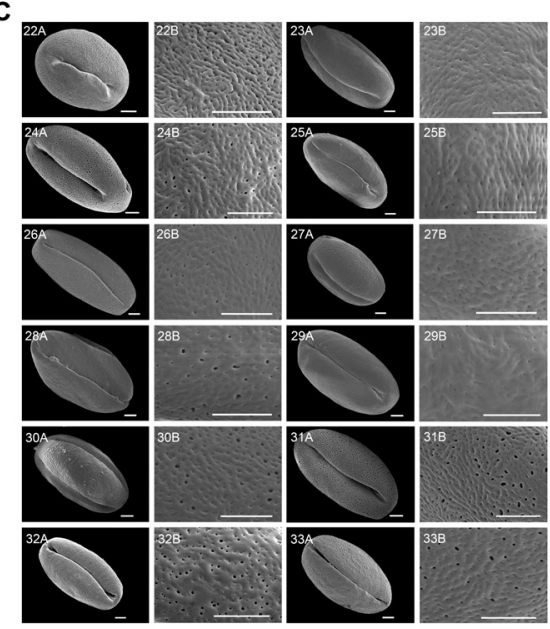

E

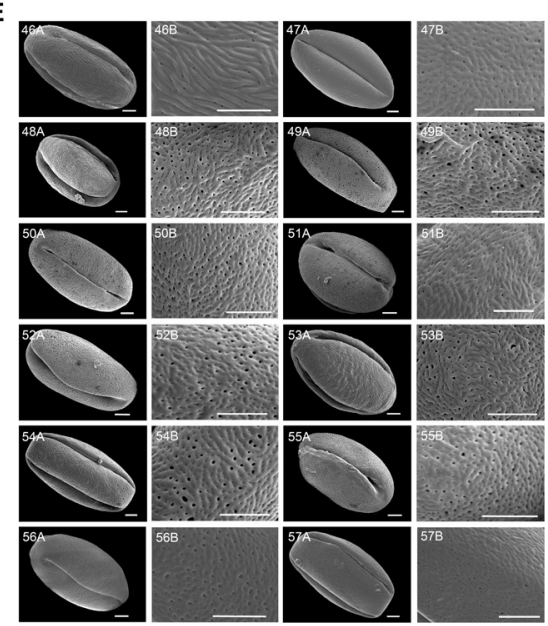

$B$

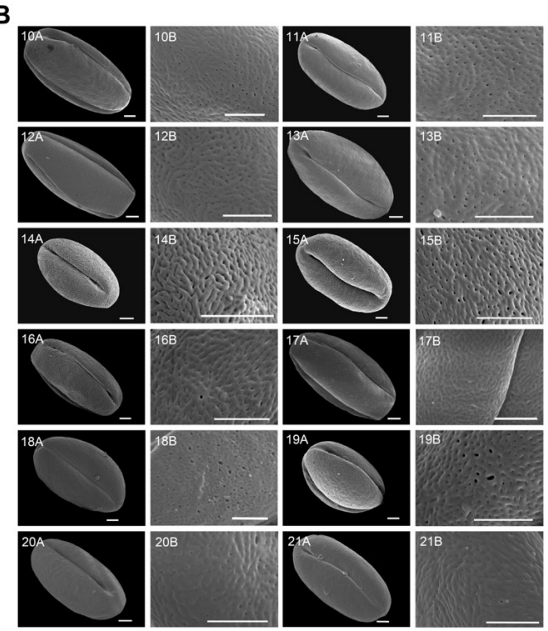

D

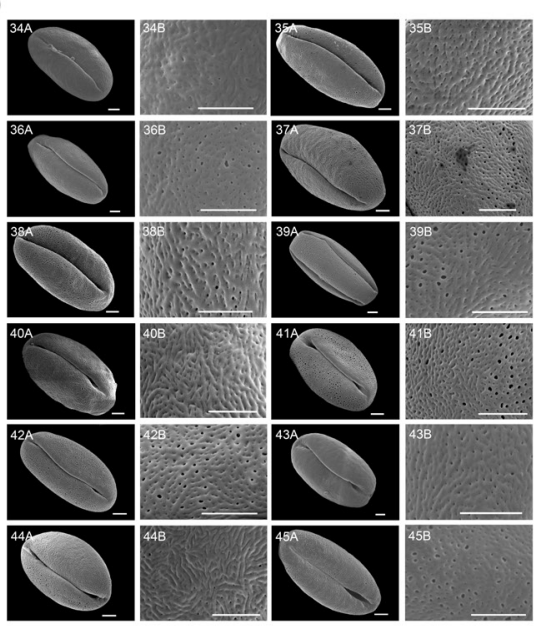

Figure 4. A. to E. SEM micrographs of 57 Chinese hawthorn cultivars (Scale bar: $5 \mu \mathrm{m}$ ).

Genetics and Molecular Research 15 (3): gmr.15038739 
The exine pattern types were defined on the basis of surface characters of the exine following Punt et al. $(1994,2007)$. Our observations showed that the exine sculpturing pattern of the pollen grains generally was striate with perforations (Figure 3A and B). Among all cultivars, striate-perforate was the predominant position. The striae were cylindrical, elongated, generally parallel to the colpus, separated by grooves, interwoven, and forming bends. The grooves were quite deep, usually with widths similar to or narrower than the striae. The perforated cultivars were provided with holes less than $1 \mathrm{~mm}$ in diameter (Figure 3C). However, the details of the striate-perforate exine sculpturing pattern varied considerably between cultivars: the lirae (muri, a narrow ridge that forms the murus in a striated pattern) varied in size. The width, proximity, orientation of lirae, frequency of anastomoses, and the groove width varied in size, and the perforations varied in size and frequency. Numerous elliptic or circular perforations of varying, relatively substantial diameters were present in the pollen grains. In addition, some other exine pattern types were also observed: rugulate (Figure 3D, with elongated elements more than $1 \mathrm{~mm}$ long, arranged in an irregular pattern between striate and reticulate) and microreticulate (with a network-like pattern with meshes smaller than $1 \mathrm{~mm}$ in diameter). Details of pollen exine sculpturing are given in Table 4 and Figure 4A-E (panels B).

\section{Correlation analysis among plant morphology traits}

The study of the relationships among traits is beneficial for breeding programs. Established relationships between some traits can help breeders in setting objectives for parental partner selection and breeding (Khadivi-Khub et al., 2015). The results of our correlation analysis between the plant morphological characteristics of the 57 Chinese hawthorn cultivars are shown in Table 5.

The leaf blade length was highly and positively correlated with the leaf blade width ( $\mathrm{r}$ $=0.758)$ and petiole length $(r=0.723)$. In addition, strong positive correlations were observed among the fruit traits; the correlation between fruit length and fruit width was significant $(r=$ $0.798)$. A positive correlation was also found between the fruit length and the endocarp length $(\mathrm{r}=0.348)$, whereas a negative correlation was found between fruit width and fruit shape index $(r=-0.468)$. Furthermore, the endocarp length correlated negatively with endocarp shape index $(r=-0.465)$, whereas the endocarp width correlated positively with endocarp shape index $(\mathrm{r}=0.652)$. A positive correlation was found between the fruit surface texture and the density of the fruit lenticels $(\mathrm{r}=0.514)$. Leaf blade lobes showed a significant positive correlation with fruit shape index $(\mathrm{r}=0.517)$. In contrast, a negative correlation was observed between leaf blade lobes and fruit length $(r=-0.456)$.

\section{PCA results}

Based on the correlation matrix, the first 11 PCs had an eigenvalue greater than 1 and these PCs together accounted for $76.26 \%$ of the total variation in the data (Table 6 ). The results revealed a great morphological variation, indicating high genetic diversity between the cultivars. This suggests that it is necessary to evaluate the different morphological traits for a meaningful characterization. The first component, PC1, explained $15.92 \%$ of the total variation, followed by 11.10 and $9.63 \%$ for PC2 and PC3, respectively. The fruit surface texture, fruit width, sepal shape, sepal posture, endocarp length, and delicate leaf color were found to load significantly onto PC1.

Genetics and Molecular Research 15 (3): gmr.15038739 


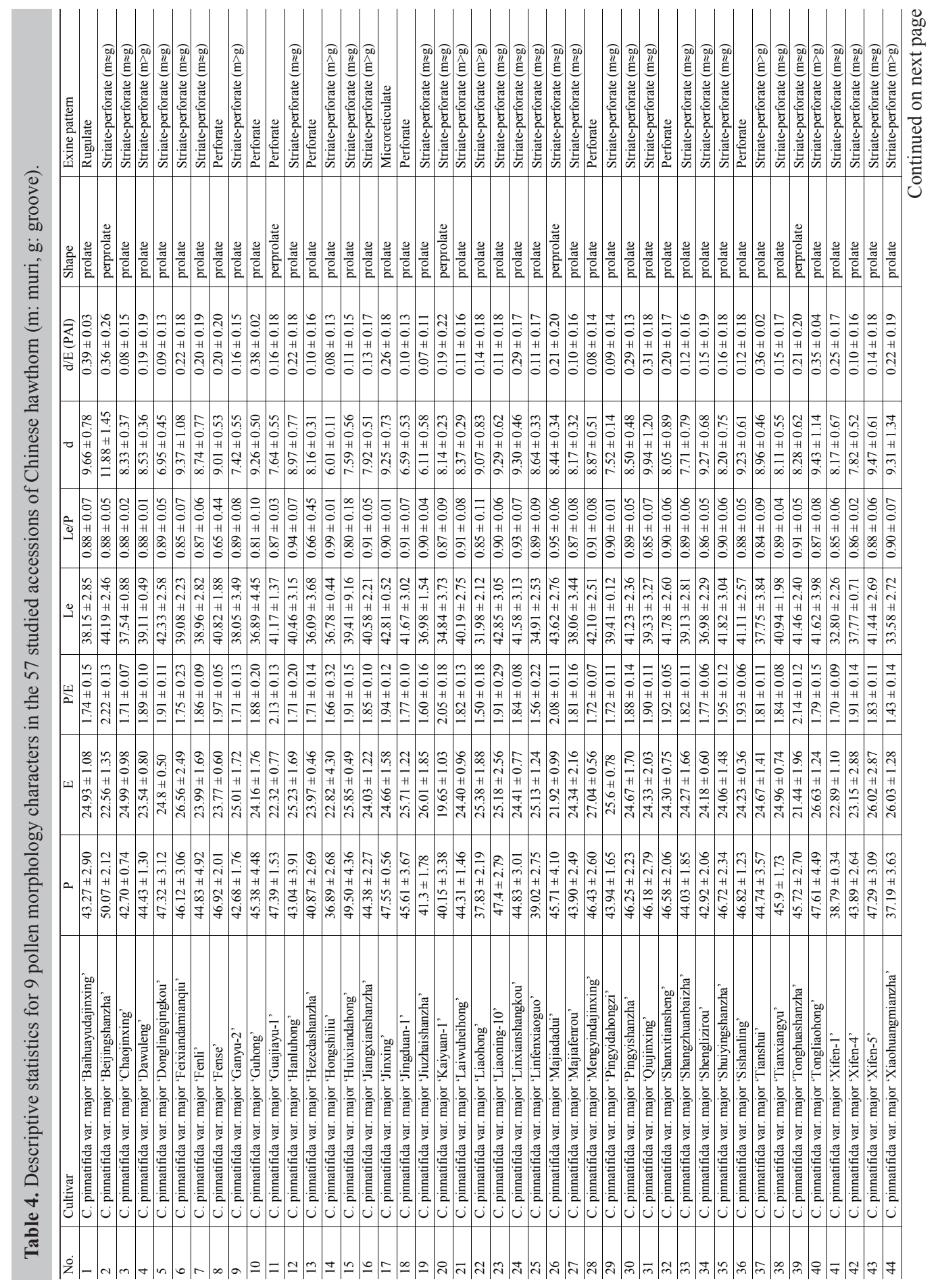

Genetics and Molecular Research 15 (3): gmr.15038739 


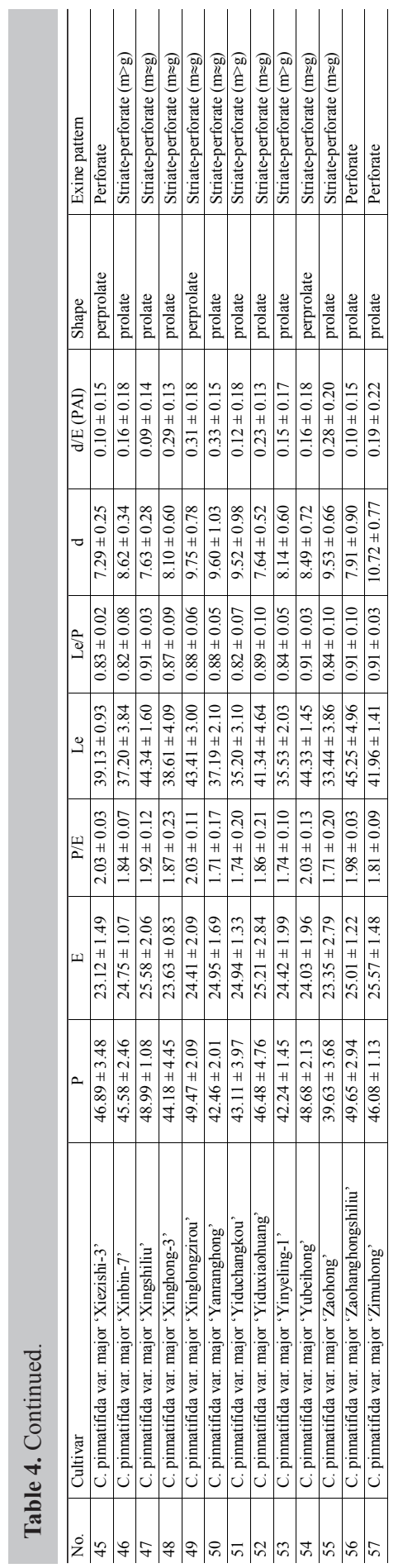

Genetics and Molecular Research 15 (3): gmr.15038739 


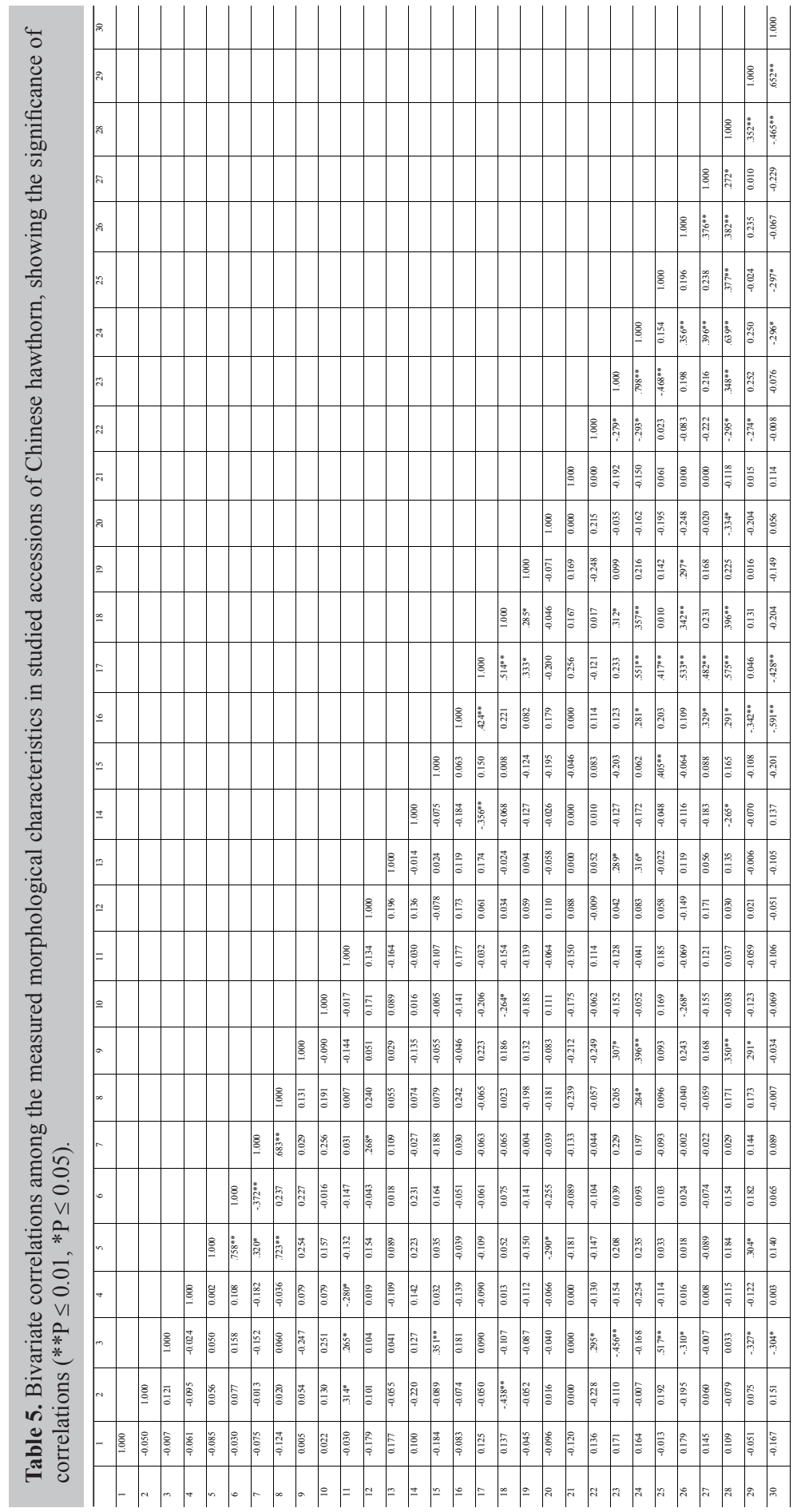


The characters that loaded significantly on PC2 were leaf blade lobe, fruit width, and fruit shape index. For PC3, the highly loading traits included petiole length and leaf shape index. PC4 explained $7.58 \%$ of the total morphological variation, and was associated with both leaf length and width. PC5 explained $6.40 \%$ of the variation and was associated with three characters: fruit color, endocarp width, and endocarp shape index. The remaining PCs (PC6-11) explained 5.15, 4.73, 4.36, 4.18, 3.88, and 3.35\% of the total variation, respectively. These were strongly associated with leaf shape, density of fruit lenticels, cavity of fruit eye basin, flesh texture, and so on. The number of flowers per inflorescence and the pedicel length were taken out for they did not load significantly onto PC1-11.

Table 6. Eleven principal component (PC) rotation loadings, percentage of variance and percentage of total cumulative variance of studied accessions of Chinese hawthorn explained.

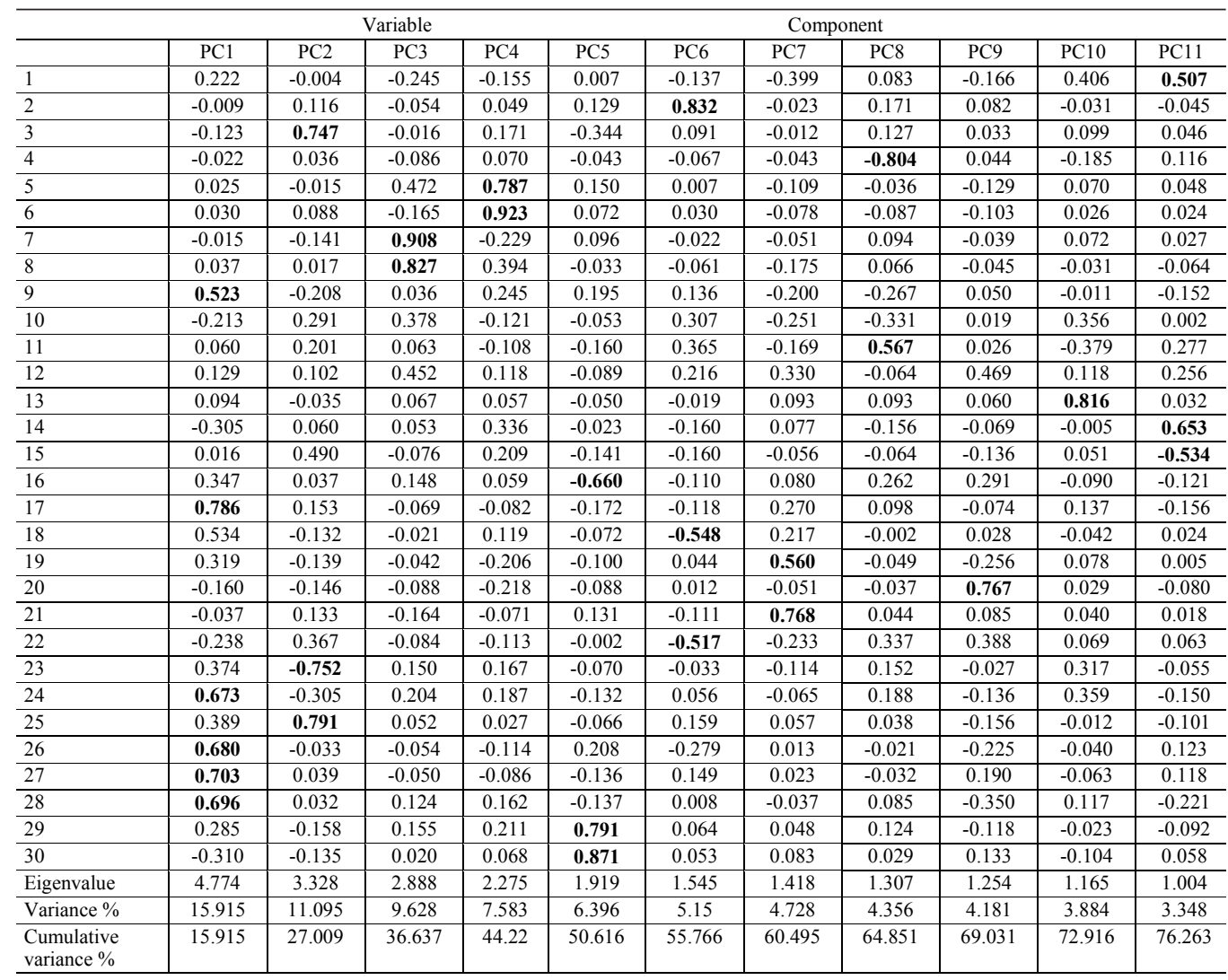

\section{Q-cluster analysis of Chinese hawthorn cultivars}

As shown in Figure 5, 57 cultivars were clustered into eight groups based on the plant morphological traits. The first cluster included most of the cultivars; the second category included No. 49 'Xinglongzirou', which was the only cultivar with purple flesh. The third cluster included Nos. 7, 22, 24, 27, 35, 44, 46, 52, and 57; the fourth cluster included No. 29 
'Pingyidahongzi'; the fifth cluster included Nos. 6, 16, and 34;. The sixth cluster included Nos. $8,23,32,50$, and 55; which had similar characteristics in fruits: dense fruit lenticels, soft fruit flesh, tubercle one side at stalk base, open cavity of eye basin, and so on. The seventh cluster included Nos. 40 and 42, whereas the eighth cluster consisted of Nos. 2 and 14.

A further cluster analysis was performed using pollen morphological traits (Figure $6)$. Again, the 57 cultivars clustered into eight groups. The codes used for the cluster analysis were: shape (1: prolate, 2 : perprolate) and exine pattern [1: rugulate, 2 : striate-perforate $(\mathrm{m} \approx \mathrm{g})$, 3: striate-perforate $(\mathrm{m}>\mathrm{g}), 4$ : perforate, and 5: microreticulate]. The first and fourth clusters included most of the cultivars; the second cluster consisted of No. 15 'Huixiandahong'. The third cluster included Nos. 2, 47, 49, 54, and 56. The ratio of P/E of this cluster was larger (about 2 ), and the exine pattern was striate-perforate $(\mathrm{m} \approx \mathrm{g})$, except No. 56 (perforate). The fifth cluster included Nos. 13, 19, 51, and 53. The sixth cluster contained Nos. 22, 25, 41, 44, and 55. The seventh and eighth clusters contained No. 14 'Hongshiliu' and 20 'Kaiyuan-1', respectively. The ratio of Le/P was maximal in 'Hongshiliu' (0.99), which indicated that the length of ectocolpi was long and close to the length of polar axis.

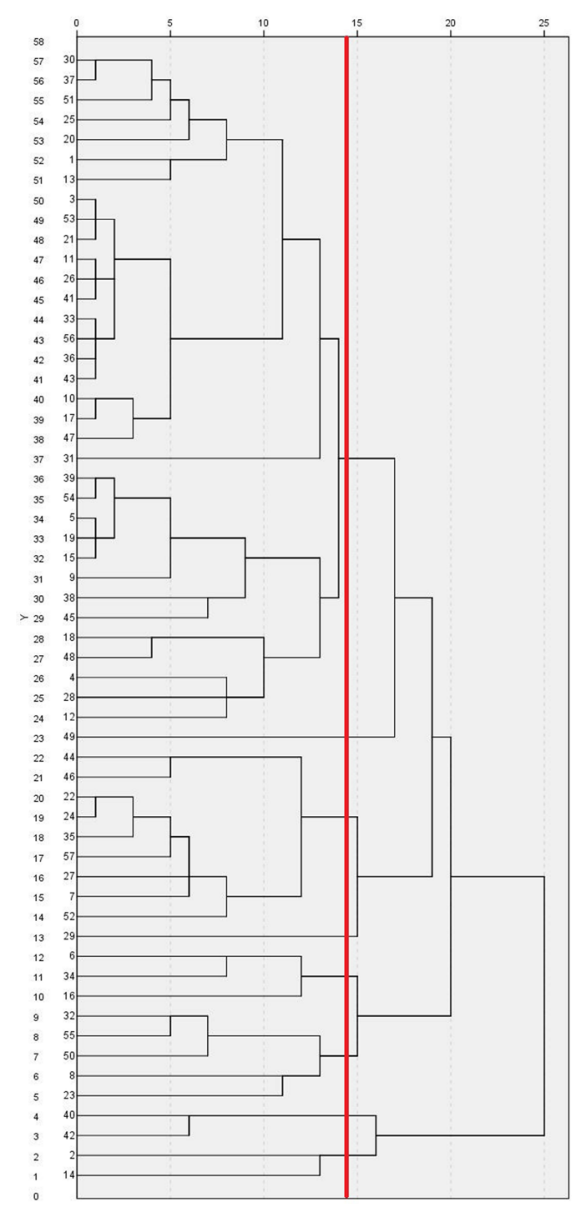

Figure 5. Q-cluster analysis of Chinese hawthorn cultivars via phenotypic traits.

Genetics and Molecular Research 15 (3): gmr.15038739 


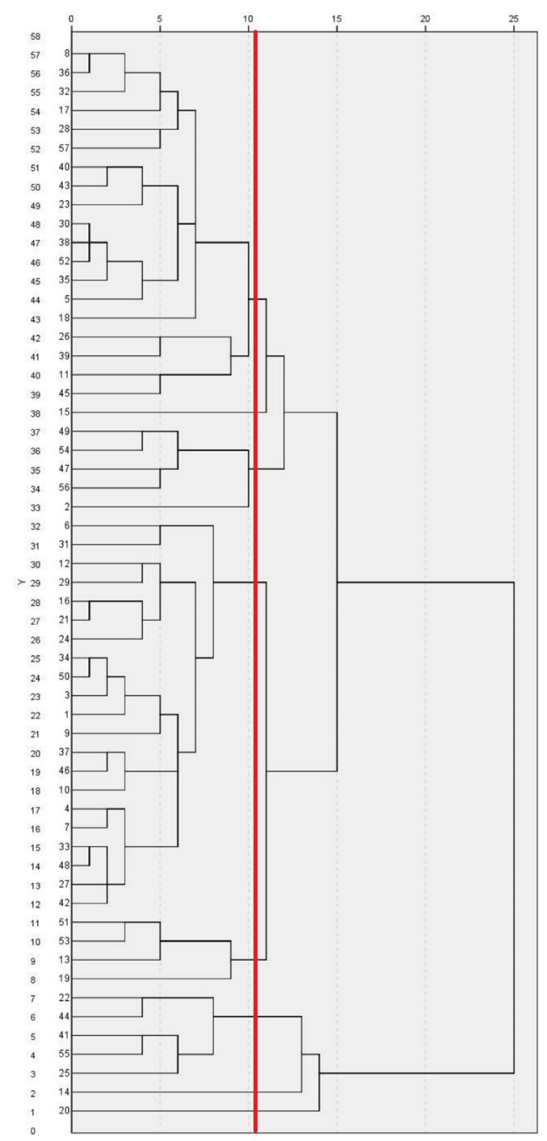

Figure 6. Q-cluster analysis of Chinese hawthorn cultivars via pollen morphological traits.

\section{DISCUSSION}

Palynological studies on intraspecific hybrids have focused on both artificial and spontaneous hybrids. However, palynological studies have rarely included cultivars. Several studies have examined the pollen morphology of European Crataegus species (Reitsma, 1966; Byatt, 1976), whereas others have studied that of North American species (Dickinson and Phipps, 1986; Hebda et al., 1988; Hebda and Chinnappa, 1990). Hebda et al. (1988) studied Crataegus in western Canada and found that Crataegus pollen had pores with a typical equatorial bridge or flaps when open. Furthermore, the pollen of native North American Crataegus species: $C$. douglasii, $C$. rotundifolia, and $C$. succulenta showed morphological variability. In subsequent studies, Hebda and Chinnappa (1990) found that pollen exine sculpturing of parallel ridges and valleys containing perforations predominated. The perforations were large and often extending onto the tectal ridges. Christensen (1992) provided a short pollen description based on the examination of several Eurasian taxa of the genus. The pollen study by Byatt (1976) included a specimen of C. stevenii Pojark. from Turkey. Dönmez (2008), examining the pollen morphology of Turkish Crataegus taxa, did not observe a significant increase in pollen size

Genetics and Molecular Research 15 (3): gmr.15038739 
in polyploid species. The pollen of Chinese hawthorn varieties, however, have received little attention to date. Xin et al. (1986) and Zhou et al. (2000) investigated the pollen morphology of hawthorn grown in China. Hamideh et al. (2012) studied microsporogenesis and pollen morphology in C. babakhanloui. The results obtained from the above mentioned studies generally agreed with our results.

Studies on Chinese hawthorn carried out by us have suggested that the pollen grains are variable. Pollen grains of Chinese hawthorns investigated here were found in radially symmetrical monads. While tricolporate was the most frequent pollen type, tricolpate, trisyncolporate, and other pollen types were also observed. Pollen grain sizes were mostly medium sized, rarely small or large. The pollen shape (P/E ratio) was prolate, rarely perprolate. And the exine sculpturing was striated with perforations on the grain surface. Many different exine sculpture types have been found in Crataegus, including regulate, perforate, rugulatestriate-perforate, and microreticulate.

While previous classification treatments of Chinese hawthorn were based mainly on plant morphological traits, the present study also presents results of a detailed morphological investigation of Chinese hawthorn pollen, based on the examination of multiple specimens by SEM together with size measurements. We paid particular attention to the exine patterns, describing surface features of pollen grains. This was done because these features may vary from variety to variety. Nevertheless, the analysis of classification and phylogeny of Chinese hawthorn is a prerequisite for its exploration and utilization. This study provides a theoretical foundation and constitutes an important reference for Chinese hawthorn germplasm research, development, utilization, and cultivation of new cultivars. Conservation management of Chinese hawthorn germplasm resources are urgently needed and the results presented here may be used as a guide in this effort.

\section{Conflicts of interest}

The authors declare no conflict of interest.

\section{ACKNOWLEDGMENTS}

Research supported by the DUS Project of State Forestry Bureau of China (Guidelines for the Conduct of Tests for Distinctness, Uniformity and Stability for Crataegus, Grant \#2014-LY-020). The authors also appreciate the help from the Biotechnology Centre, Beijing Forestry University, for access to the scanning electron microscope.

\section{REFERENCES}

Albarouki E and Peterson A (2007). Molecular and morphological characterization of Crataegus L. species (Rosaceae) in southern Syria. Bot. J. Linn. Soc. 153: 255-263. http://dx.doi.org/10.1111/j.1095-8339.2007.00607.x

Byatt JI (1976). Pollen morphology of some European species of Crataegus L. and Mespilus germanica L. (Rosaceae). Pollen Spores 18: 335-349.

Campbell CS, Evans RC, Morgan DR, Dickinson TA, et al. (2007). Phylogeny of subtribe Pyrinae (formerly the Maloideae, Rosaceae): limited resolution of a complex evolutionary history. Plant Syst. Evol. 266: 119-145. http:// dx.doi.org/10.1007/s00606-007-0545-y

Christensen KI (1983). A biometric study of some hybridizing Crataegus populations in Denmark. Nord. J. Bot. 2: 537548. http://dx.doi.org/10.1111/j.1756-1051.1983.tb01046.x

Genetics and Molecular Research 15 (3): gmr.15038739 
Christensen KI (1992). Revision of Crataegus sect. Crataegus and nothosect. Crataeguineae (Rosaceae-Maloideae) in the Old World. Systematic Botany Monographs. Vol. 35. American Society of Plant Taxonomists, Ann Arbor.

Christensen KI and Zieliński J (2008). Notes on the genus Crataegus (Rosaceae-Pyreae) in southern Europe, the Crimea and western Asia. Nord. J. Bot. 26: 344-360. http://dx.doi.org/10.1111/j.1756-1051.2008.00330.x

Dai H, Zhang Z and Guo X (2007). Adventitious bud regeneration from leaf and cotyledon explants of Chinese hawthorn (Crataegus pinnatifida Bge. var. major N.E.Br.). In Vitro Cell. Dev. Biol. Plant 43: 2-8. http://dx.doi.org/10.1007/ s11627-006-9008-3

Dai H, Guo X, Zhang Y, Li Y, et al. (2009). Application of random amplified polymorphic DNA and inter-simple sequence repeat markers in the genus Crataegus. Ann. Appl. Biol. 154: 175-181. http://dx.doi.org/10.1111/j.17447348.2008.00290.X

Dai H, Han G, Yan Y, Zhang F, et al. (2013). Transcript assembly and quantification by RNA-Seq reveals differentially expressed genes between soft-endocarp and hard-endocarp hawthorns. PLoS One 8: e72910. http://dx.doi. org/10.1371/journal.pone.0072910

Dickinson TA and Phipps JB (1986). Studies in Crataegus (Rosaceae, Maloideae), XIV. The breeding system of Crataegus crus-galli sensu lato in Ontario. Am. J. Bot. 73: 116-130. http://dx.doi.org/10.2307/2444284

Dönmez EO (2008). Pollen morphology in Turkish Crataegus (Rosaceae). Bot. Helv. 118: 59-70. http://dx.doi.org/10.1007/ $\underline{\mathrm{s} 00035-008-0823-5}$

Du YP, Wei C, Wang ZX, Li S, et al. (2014). Lilium spp. pollen in China (Liliaceae): taxonomic and phylogenetic implications and pollen evolution related to environmental conditions. PLoS One 9: e87841. http://dx.doi. org/10.1371/journal.pone.0087841

Erdtman G (1952). Pollen morphology and plant taxonomy. Angiosperms. Almquist \& Wiksell, Stockholm.

Fineschi S, Salvini D, Turchini D, Pastorelli R, et al. (2005). Crataegus monogyna Jacq. and C. laevigata (Poir.) DC. (Rosaceae, Maloideae) display low level of genetic diversity assessed by chloroplast markers. Plant Syst. Evol. 250: 187-196.

Guo TJ and Jiao PJ (1995). Hawthorn (Crataegus) resources in China. HortScience 30: 1132-1134.

Hamideh R, Ahmad M, Sedigheh A, Fariba S, et al. (2012). A study of microsporogenesis and pollen morphology in Crataegus babakhanloui (Rosaceae). Adv. Environ. Biol. 6: 2986-2991.

Hebda RJ and Chinnappa CC (1990). Studies on pollen morphology of Rosaceae in Canada. Rev. Palaeobot. Palynol. 64: 103-108. http://dx.doi.org/10.1016/0034-6667(90)90123-Z

Hebda RJ, Chinnappa CC and Smith BM (1988). Pollen morphology of the Rosaceae of Western Canada I. Agrimonia to Crataegus. Grana 27: 93-113. http://dx.doi.org/10.1080/00173138809432836

Judd WS, Campbell CS, Kellogg EA and Stevens PF (1999). Plant systematics. A phylogenetic approach. Sinauer Associates, Inc., Sunderland.

Kao ES, Wang CJ, Lin WL, Yin YF, et al. (2005). Anti-inflammatory potential of flavonoid contents from dried fruit of Crataegus pinnatifida in vitro and in vivo. J. Agric. Food Chem. 53: 430-436. http://dx.doi.org/10.1021/jf040231f

Khadivi-Khub A, Karimi S and Kameli M (2015). Morphological diversity of naturally grown Crataegus monogyna (Rosaceae, Maloideae) in Central Iran. Braz. J. Bot. 38: 921-936. http://dx.doi.org/10.1007/s40415-015-0187-1

Lo EYY (2008). Global and fine scale molecular studies of polyploidy evolution in Crataegus L. (Rosaceae). Doctoral thesis, University of Toronto, Toronto.

Muller J (1979). Form and function in angiosperm pollen. Ann. Mo. Bot. Gard. 66: 593-632. http://dx.doi. org $/ 10.2307 / 2398913$

Phipps JB (1988). Crataegus (Maloideae, Rosaceae) of the southeastern United States, I. Introduction and series Aestivales. J. Arnold Arbor. 69: 401-431.

Phipps JB (2005). A review of hybridization in North American hawthorns - Another look at 'the Crataegus problem'. Ann. Mo. Bot. Gard. 92: 113-126.

Phipps JB, Robertson KR, Rohrer JR and Smith PG (1991). Origin and evolution of subfam. Maloideae (Rosaceae). Syst. Bot. 16: 303-332. http://dx.doi.org/10.2307/2419283

Punt W, Blackmore S, Nilsson S and Le Thomas A (1994). Glossary of pollen and spore terminology. LPP Foundation, Utrecht.

Punt W, Hoen PP, Blackmore S, Nilsson S, et al. (2007). Glossary of pollen and spore terminology. Rev. Palaeobot. Palynol. 143: 1-81. http://dx.doi.org/10.1016/j.revpalbo.2006.06.008

Reitsma TJ (1966). Pollen morphology of some European Rosaceae. Acta Bot. Neerl. 15: 290-307. http://dx.doi. org/10.1111/j.1438-8677.1966.tb00234.x

Rigelsky JM and Sweet BV (2002). Hawthorn: pharmacology and therapeutic uses. Am. J. Health Syst. Pharm. 59: 417-422.

Wang JM, Ma SLY, Li WQ, Wang Q, et al. (2016). Genetic variability and diversity of the main resources of lily assessed via phenotypic characters, pollen morphology, and ISSR markers. Genet. Mol. Res. 15: 10.4238/gmr.15027638.

Genetics and Molecular Research 15 (3): gmr.15038739 
Wrońska-Pilarek D, Bocianowski J and Jagodziński AM (2013). Comparison of pollen grain morphological features of selected species of the genus Crataegus (Rosaceae) and their spontaneous hybrids. Bot. J. Linn. Soc. 172: 555-571. http://dx.doi.org/10.1111/boj.12033

Xin X, Zhang YM and Wang J (1986). Observations on the pollen morphology of major Crataegus species in China. Zhongguo Nong Ye Ke Xue 3: 94-95.

Zhao HC and Feng BT (1996). China fruit-plant monograph of Hawthorn (Crataegus) flora. Zhongguo Linye Press, Beijing.

Zhou LH, Wie ZX and Wu ZY (2000). Pollen morphology of Maloideae of China (Rosaceae). Acta Bot. Yunnan. 22: 47-52.

Genetics and Molecular Research 15 (3): gmr.15038739 